\title{
Growth and development of the corpus luteum
}

\author{
L. P. Reynolds and D. A. Redmer \\ Department of Animal \& Range Sciences, \\ North Dakota State University, Fargo, ND 58105-5727, USA
}

\begin{abstract}
The mammalian corpus luteum, which plays a central role in the reproductive process because of its production of hormones such as progesterone, is an exceptionally dynamic organ. Growth and development of the corpus luteum are extremely rapid, and even when the corpus luteum is functionally mature cellular turnover remains high. Associated with this high rate of cell turnover, the mature corpus luteum receives the greatest blood supply per unit tissue of any organ, and also exhibits a relatively high metabolic rate. Central to the growth and development of the corpus luteum, therefore, is luteal vascular growth, which appears to be regulated primarily by the angiogenic growth factors, basic fibroblast growth factor and vascular endothelial growth factor. In addition, the corpus luteum is a complex tissue composed of parenchymal (small and large steroidogenic) and nonparenchymal (for example fibroblasts, vascular smooth muscle, pericytes and endothelial) cells. Recent studies evaluating the expression, location and regulation of gap junctions in the corpus luteum indicate an important role of gap junctional intercellular communication in the coordination of function among these diverse cell types during luteal growth and development. These studies will lead to an improved understanding not only of luteal function but also of tissue growth and development in general.
\end{abstract}

\section{Introduction}

The corpus luteum is a transient endocrine gland that is formed from the cells of the ovarian follicle after ovulation (Niswender and Nett, 1988; Reynolds et al., 1994). In mammals, the principal function of the corpus luteum is to secrete progesterone, during the nonpregnant cycle as well as during pregnancy (Niswender and Nett, 1988; Reynolds et al., 1994). In fact, the concentration of progesterone in systemic blood is used as an index of luteal function (Niswender and Nett, 1988; Reynolds et al. 1994). In the nonpregnant animal, progesterone inhibits pituitary gonadotrophin secretion and thereby regulates the duration of the oestrous or menstrual cycle (Niswender and Nett, 1988; Reynolds et al., 1994). During pregnancy, progesterone relaxes the uterine smooth muscle, stimulates uterine growth and secretory activity, influences maternal metabolism and mammary development, and is a precursor for other gestational steroids, all of which serve to support the developing embryo or fetus as well as the resulting offspring (Niswender and Nett, 1988; Reynolds et al., 1994). Inadequate luteal function, therefore, leads to death of the embryo or fetus in most mammalian species (Niswender et al., 1985; Niswender and Nett, 1988; Reynolds et al., 1994).

The corpus luteum is one of the few adult tissues that exhibits regular periods of growth and development (Hudlicka, 1984; Jablonka-Shariff et al., 1993; Reynolds et al., 1994). In addition, growth and development of the corpus luteum are extremely rapid. For example, immediately after ovulation the corpus luteum of the ewe weighs about $30-40 \mathrm{mg}$. By day 12 of the oestrous cycle (that is, 12 days after ovulation), the corpus luteum reaches a maximum weight of about $750 \mathrm{mg}$, which represents a 20 -fold increase in tissue mass over 12 days. On the basis of several studies of luteal growth and development, the doubling time for luteal tissue mass during this rapid growth phase is about 60-70 h (Reynolds et al., 1994). Such rapid growth is equalled only by the fastest growing tumours (Baserga, 1985; Reynolds et al., 1994). However, in contrast to tumour growth, growth of the 
corpus luteum is a self-limiting and highly ordered process. Thus, whereas growth of the corpus luteum has stopped by mid-cycle, luteal blood flow and progesterone secretion are maximal (Reynolds et al., 1994).

An improved understanding of luteal function obviously has important implications for the regulation of fertility in mammals. In addition, because the corpus luteum is so dynamic, it provides an ideal model for studying the regulation of tissue growth and development, thereby leading to an improved understanding of these processes not only in the normal state but also in abnormal conditions such as in tumour growth or other pathologies (Reynolds et al., 1992, 1994).

\section{Luteal Growth and Development}

\section{General aspects}

The corpus luteum is a complex tissue composed of parenchymal (small and large steroidogenic) and nonparenchymal (for example fibroblasts, vascular smooth muscle, pericytes and endothelial) cells (Niswender and Nett, 1988). In a complex tissue, the various cell types must interact to ensure normal growth and development (Hudlicka, 1984; Baserga, 1985). For example, tissue growth depends upon growth of new blood vessels and establishment of a functional blood supply (Hudlicka, 1984; Reynolds et al., 1992). Growth of the vascular bed, in turn, must be highly coordinated with the metabolic demands of the tissue, since either rampant or insufficient vascular growth invariably leads to a pathological condition (Hudlicka, 1984; Reynolds et al, 1992). Coordination among the various cell types is accomplished through several means, including humoral mechanisms involving endocrine or paracrine factors, as well as direct communication via gap junctions (Grazul-Bilska et al., 1997, 1998a). However, before the role of these various factors can be determined, the normal patterns of tissue growth must be understood.

The corpus luteum is formed from the remnant of the ovarian follicle after ovulation and exhibits rapid growth until reaching its mature size around mid-cycle (Fig. 1; Reynolds et al., 1994). At least in domestic ruminants, if pregnancy is established successfully the size of the corpus luteum remains relatively constant throughout most of gestation (Reynolds et al., 1994), and thus as mentioned previously the growth of the corpus luteum appears to be self-limiting (Reynolds et al., 1994). In fact, in mammals the total luteal weight is species specific and related to body size (Fig. 2). Although size of the mature corpus luteum is relatively constant within a species under normal circumstances (Fig. 2; Reynolds et al., 1994), it does not seem to be absolutely fixed, but rather is reduced when increased numbers of corpora lutea are present such as in superovulated cows and ewes, and is increased when total numbers of corpora lutea are decreased such as after unilateral ovariectomy of pregnant pigs (Reynolds et al., 1994).

\section{Cellular aspects}

During the luteal growth phase, luteal weight and DNA content increase exponentially (Fig. 1). The labelling index (rate of DNA synthesis) of the early, rapidly growing corpus luteum is extremely high compared with that of other tissues and is comparable with that of growing tumours and regenerating tissues (for example regenerating liver; Baserga, 1985; Jablonka-Shariff et al., 1993; Zheng et al., 1994; Reynolds et al., 1994).

Even though the labelling index of the corpus luteum decreases markedly by mid-cycle, the number of proliferating luteal cells remains relatively constant because of the increase in the number of cells (Table 1). In spite of the continued proliferation of large numbers of luteal cells, however, weight, DNA content or total numbers of cells do not continue to increase in the mature corpus luteum (Fig. 1; Niswender et al., 1985; Farin et al., 1986; Jablonka-Shariff et al., 1993; Zheng et al., 1994; Reynolds et al., 1994; Ricke, 1995). After mid-cycle, therefore, the mature corpus luteum appears to remain a very dynamic tissue, which exhibits a high rate of cell turnover (Reynolds et al., 1994). Whether this high rate of cell turnover continues during pregnancy is not known; however, 


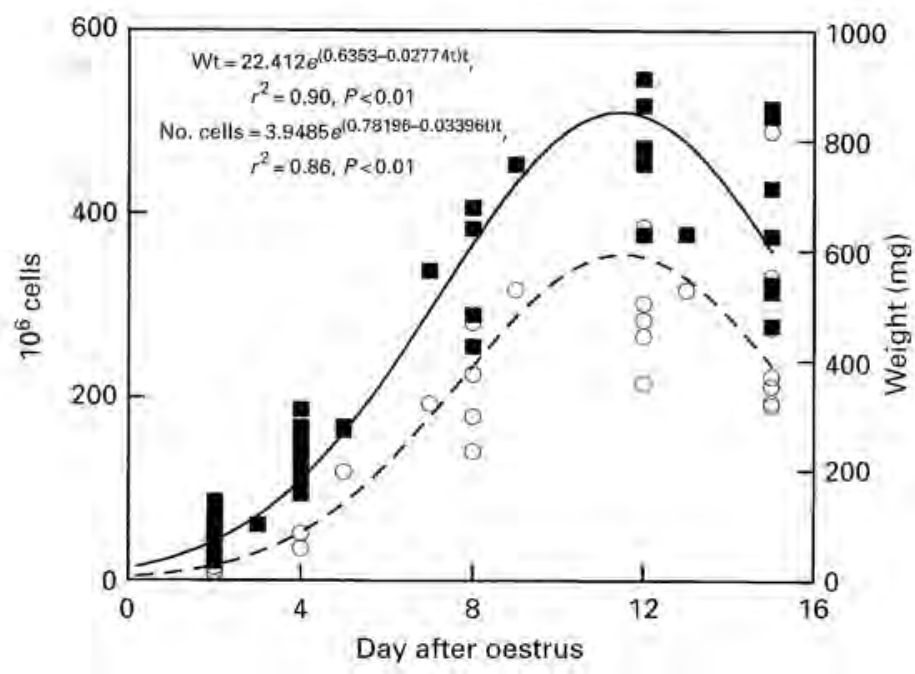

Fig. 1. Regression analysis of weight ( $)$ and number of cells $(O)$ for sheep corpora lutea throughout the oestrous cycle. The exponential growth model was of the form $y=n e^{(21-k 2) t}$, where $y=$ weight or number of cells at time $=i, a=$ weight or number of cells at time $=0$, and $k_{1}$ and $k_{2}$ are exponential growth constants. Data are adapted from Jablonka-Shariff et al. (1993).

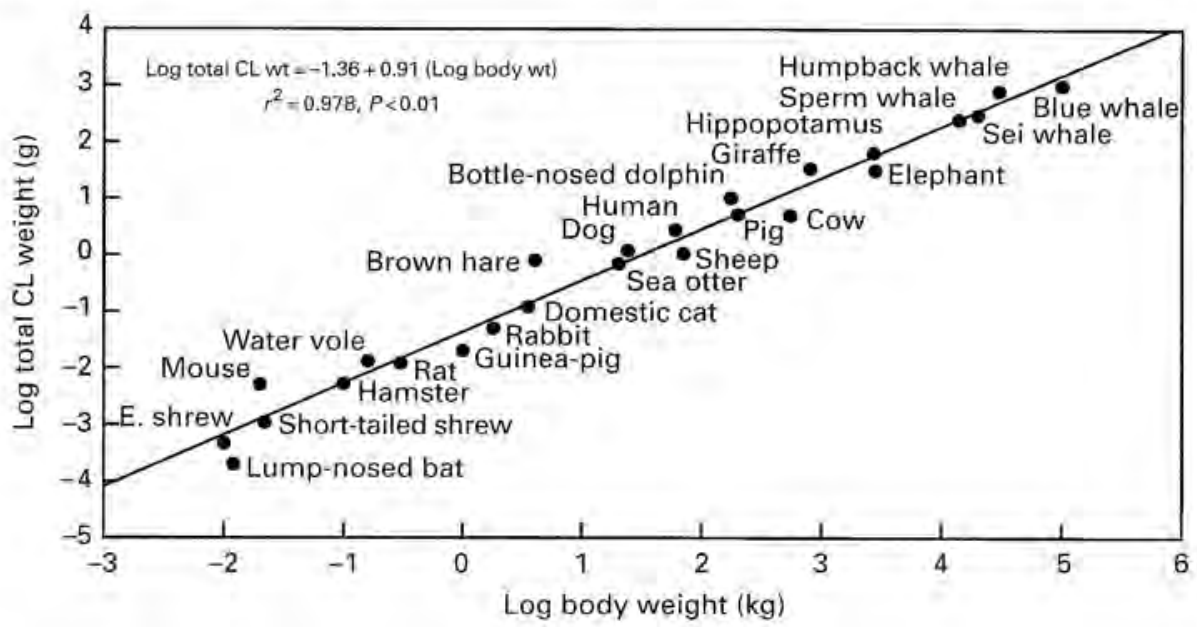

Fig. 2. Regression analysis of $\log$ of total weight of corpus luteum versus log of body weight in various. mammals. Data for body weights are taken from Walker's Mammals of the World (1991) 5th Edn (Ed. RM Nowak, Johns Hopkins University Press, Baltimore). Data for total weight of corpus luteum are taken from various sources and represent maximal weights attained during the nonpregnant cycle or early pregnancy; when weight was not given it was estimated by assuming that $1 \mathrm{~mm}^{3}=1 \mathrm{mg}$ and $1 \mathrm{~cm}^{3}=1 \mathrm{~g}$.

morphological descriptions as well as quantitative morphometry have indicated that this may be the case (Reynolds et al., 1994; Jablonka-Shariff et al., 1997).

Luteal differentiation also occurs rapidly, and luteinization of the follicular cells that will form the corpus luteum and the associated progesterone production by these cells begin before ovulation (Gore-Langton and Armstrong, 1988). In addition, expression of 33-hydroxysteroid dehydrogenase, a key enzyme in progesterone synthesis, is high in a large proportion of luteal cells soon after 
Table 1. Kinetics of luteal cell proliferation in domestic livestock

\begin{tabular}{lcccc}
\hline Species & Day after oestrus & No. of animals & No. of cells $\left(\times 10^{6}\right)$ & Dividing cells $\left(\times 10^{6} /\right.$ day $)$ \\
\hline Sheep & 2 & 12 & 16 & 12 \\
& 4 & 12 & 91 & 42 \\
& 8 & 6 & 223 & 38 \\
& 12 & 6 & 296 & 31 \\
& 15 & 7 & 274 & 4 \\
Cow & 2 & 5 & 177 & 78 \\
& 14 & 5 & 1394 & 106 \\
& 14 & 5 & 1631 & 117 \\
& 20 & 5 & 328 & 24 \\
Pig & 2 & 6 & 67 & 35 \\
& 4 & 7 & 97 & 38 \\
& 8 & 7 & 150 & 33 \\
& 12 & 6 & 155 & 27 \\
& 15 & 7 & 163 & 32 \\
& 18 & 7 & 203 & 30 \\
\hline
\end{tabular}

Values are means and are adapted from Jablonka-Shariff et al. (1993) for sheep, Zheng et al. (1994) for cow, and Ricke (1995) for pig. Number of cells was estimated based on DNA content, and number of dividing celis was estimated by multiplying the number of cells by the in vivo labelling index (nuclear incorporation of bromodeoxyuridine during $1 \mathrm{~h}$ of pulse labelling for sheep and pig; nuclear localization of proliferating cell nuclear antigen for cow) and assuming the duration of the S-phase in vivo is approximately $11 \mathrm{~h}$ (Baserga, 1985).

ovulation (Conley et al., 1995). Although concentrations of progesterone in systemic blood do not reach maximal values until mid-cycle, the early corpus luteum is capable of producing progesterone, on a per unit tissue or per cell basis, at a rate similar to that of the mature corpus luteum (Reynolds et $a l_{,}$1994). This finding suggests that low systemic concentrations of progesterone early in the oestrous cycle may be due primarily to the relatively small tissue mass or low vascularity of the developing corpus luteum rather than to its inability to produce progesterone (Reynolds et al., 1994).

Consistent with their early differentiation, a large proportion of the steroidogenic parenchymal cells of the corpus luteum, and especially the large luteal cells, exhibit little proliferation (Farin et al., 1986; Jablonka-Shariff et al., 1993). For example, during growth of the sheep corpus luteum, large steroidogenic luteal cells do not increase in number but rather increase about three-fold in size, whereas the small steroidogenic luteal cells and luteal capillary (endothelial and pericytes) cells do not increase in size but increase about five- to six-fold in number (Fig. 3 ). In agreement with these observations, the luteal cells that continue to proliferate after mid-cycle are principally nonparenchymal cells, such as endothelial cells, fibroblasts, or possibly undifferentiated parenchymal 'stem' cells (Reynolds et al., 1994).

The rapid and maintained proliferation of luteal endothelial cells is associated with a large increase in the rate of blood flow to the corpus luteum throughout its growth (Reynolds, 1986; Reynolds et al., 1994). The mature corpus luteum is highly vascular and receives the greatest rate of blood flow, per unit tissue, of any organ (Reynolds, 1986; Zheng et al., 1993; Redmer and Reynolds, 1996; Reynolds and Redmer, 1998). In addition, in the mature corpus luteum nearly every parenchymal cell is in contact with a capillary (Reynolds et al., 1992; Redmer and Reynolds, 1996). Not surprisingly, in conjunction with its extremely high vascularity and blood flow, the mature corpus luteum also exhibits a high metabolic rate (Swann and Bruce, 1987), perhaps because of its high rates of steroid production and cell turnover. These observations again emphasize the importance of intercellular communication in coordinating cellular proliferation and function in a complex tissue such as the corpus luteum, and also emphasize the importance of evaluating function of the individual cell types rather than the tissue as a whole. 

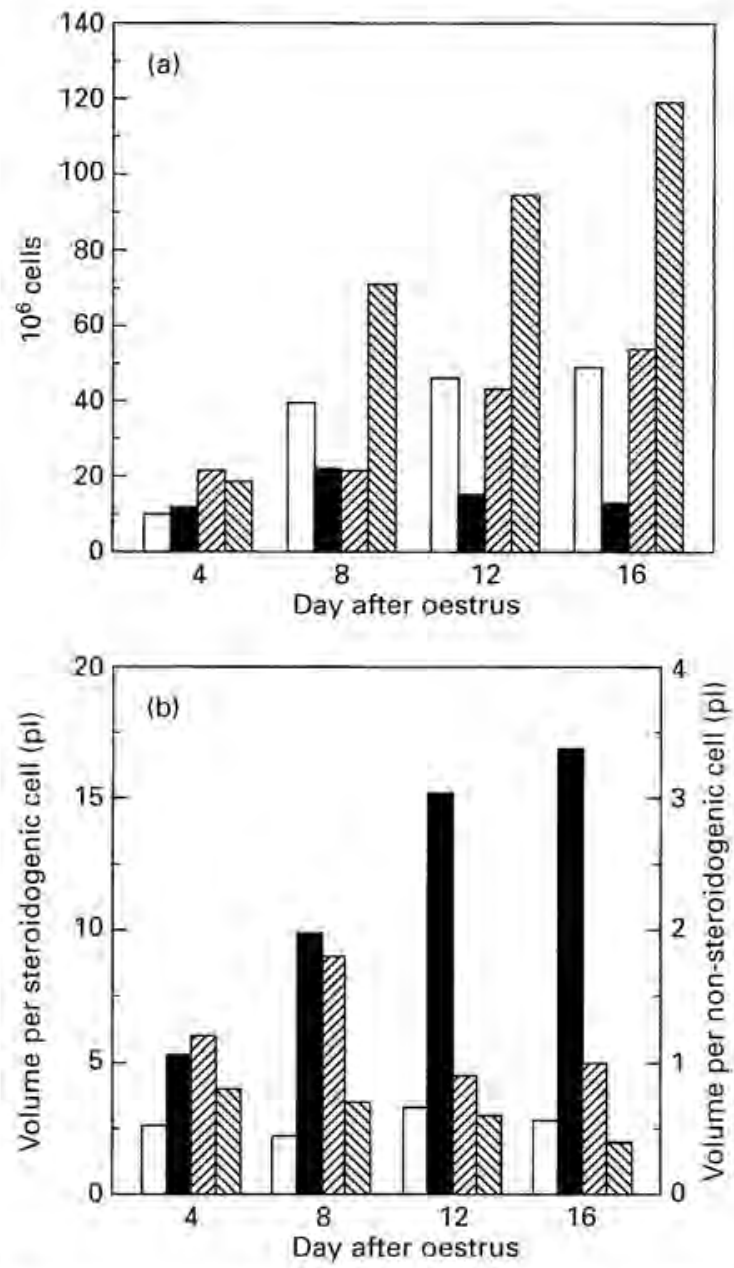

Fig. 3. Number of cells (a) and volume per cell (b) for individual cell types ( $\square$ small; $\mathbf{E}$ large; $\square$ fibroblast; and $\mathbb{N}$ endothelial and pericyte) of sheep corpus luteum throughout the oestrous cycle. Volume was estimated by assuming that $1 \mu \mathrm{m}^{3}=1$ femtolitre, Data are adapted from Farin et al. (1986).

\section{Angiogenesis in Luteal Growth and Development}

\section{General aspects}

Because the corpus luteum grows so rapidly, and because tissue growth depends on concomitant vascular growth, or angiogenesis (Hudlicka, 1984), it has long been appreciated that angiogenesis is a critical aspect of growth and function of the corpus luteum (for review, see Reynolds et al., 1992, 1994, and Redmer and Reynolds, 1996). Conversely, inadequate luteal function has been associated with decreased luteal vascularity (Reynolds et al., 1994, and Redmer and Reynolds, 1996), and several investigators have suggested that reduced ovarian blood flow plays a critical role in luteal regression (Reynolds, 1986; Niswender and Nett, 1988). Although a portion of the capillary bed degenerates during luteal regression, some of the capillaries and the larger microvessels are maintained, and these probably play an important role in resorption of the luteal tissue (Zheng et al., 1993; Ricke, 1995; Reynolds and Redmer, 1998). 


\section{Luteal angiogenic factors}

Because of the importance of vascular development in the growth, development and function of ovarian tissues, much of our research has focused on evaluating the activity and expression of luteal angiogenic factors (Redmer et al., 1988; Reynolds et al., 1992, 1994; Redmer and Reynolds, 1996). An important finding from our initial studies was that the angiogenic activity produced by bovine follicles and bovine and ovine corpora lutea binds relatively strongly to heparin-affinity columns (Reynolds et al., 1992, 1994; Redmer and Reynolds, 1996).

Thus, we hypothesized that these ovarian angiogenic factors belong to one of the families of heparin-binding angiogenic factors, namely the fibroblast growth factors (FGF) or the vascular endothelial growth factors (VEGF), rather than to one of the other families of growth factors found in the ovary (Reynolds et al., 1992, 1994; Redmer and Reynolds, 1996). This hypothesis is consistent with the suggestion that FGF and VEGF are probably key mediators of the angiogenic process in a variety of tissues (Klagsbrun and D'Amore, 1991; Reynolds et al., 1992, 1994; Redmer and Reynolds, 1996; Ferrara and Davis-Smyth, 1997; Reynolds and Redmer, 1998).

\section{Basic fibroblast growth factor}

Basic FGF (bFGF) protein is present in bovine and ovine corpora lutea (Grazul-Bilska et al., 1992; Zheng et al., 1993; Schams et al., 1994; Jablonka-Shariff et al.; 1997). Basic FGF also stimulates proliferation of bovine and ovine luteal endothelial cells, especially those from early in the cycle (Gospodarowicz et al, 1986; Grazul-Bilska et al., 1995). In addition, in the bovine corpus luteum the pattern of expression of bFGF mRNA closely follows that of production of angiogenic activity, and both increase throughout the oestrous cycle and in response to LH (Redmer et al., 1987, 1988; Stirling et al., 1991). Moreover, the majority (approximately $82 \%$ ) of the endothelial mitogenic activity produced by bovine, ovine and porcine corpora lutea was neutralized by antibodies against bFGF (Ricke, 1995; Redmer and Reynolds, 1996; Reynolds and Redmer, 1998). This last observation is important because endothelial proliferation is one of the critical components of an angiogenic response (Hudlicka, 1984; Klagsbrun and D'Amore, 1991).

However, if bFGF is one of the major angiogenic factors in the corpus luteum, it was not clear why the amounts of its mRNA and protein remain constant or even increase throughout the oestrous cycle, even though most luteal vascular development occurs in the early corpus luteum (Zheng et al., 1993; Reynolds et al, 1994; Ricke, 1995; Doraiswamy, 1998). To attempt to solve this conundrum, we recently evaluated luteal expression of the two major FGF receptors (FGFR) in ovine corpus luteum (Doraiswamy, 1998).

FGFR-1 was present in the luteal vasculature throughout the oestrous cycle; in parenchymal cells, it was present during early and mid-cycle, but was barely detectable late in the oestrous cycle. Conversely, FGFR-2 was present in the parenchymal cells at all stages, but localized to the larger microvessels only late in the oestrous cycle. We therefore hypothesized that bFGF may affect the function of not only luteal endothelial cells but also other luteal cell types, which is consistent with the ability of bFGF to stimulate progesterone production by bovine and ovine luteal cells (Grazul-Bilska et al,, 1995; Reynolds and Redmer, 1998). In addition, as mentioned above, some of the capillaries and larger microvessels of the corpus luteum are maintained late in the oestrous cycle to enable resorption of the regressing luteal tissue. The FGFs have been shown to inhibit cell death in granulosal cells (Tilly et al., 1992) as well as in other types of cell (Gospodarowicz et al., 1976; Yasuda et al., 1995). Thus, the maintenance of FGFR in the luteal microvessels could explain why they are maintained while the other luteal tissues regress (Doraiswamy et al., 1998; Reynolds and Redmer, 1998).

\section{Vascular endothelial growth factor}

It has become clear during the last decade that the VEGF family of proteins play a pivotal role in the angiogenic process (Ferrara and Davis-Smyth, 1997). The VEGF are specific stimulators of vascular permeability, and endothelial cell protease production, migration and proliferation, all of 
which are critical components of angiogenesis, and VEGF receptors Iocalize exclusively to endothelial cells. Exogenous VEGF will stimulate vascular growth in a variety of in vivo models, and VEGF mRNA is markedly increased in numerous tissues during normal and pathological angiogenesis. In addition, a number of hormones, growth factors and cytokines that may be involved in the angiogenic process have been shown to stimulate VEGF expression (Reynolds and Redmer, 1998). Moreover, hypoxia, which is thought to be a primary stimulus for tissue angiogenesis, strongly induces VEGF gene expression (Ferrara and Davis-Smyth, 1997).

More recently, treatment with VEGF-neutralizing monoclonal antibodies in vivo was shown to block the growth and reduce the vascularity of a variety of tumours in mice, even though these same antibodies did not affect the growth of tumour cells in vitro (Kim et al., 1993). In addition, disruption of the genes for VEGF receptors resulted in embryonic death by about day 8 of pregnancy in mice (Fong et al., 1995; Shalaby et al., 1995). Similarly, homozygous or heterozygous gene knockouts for VEGF were lethal by about day 11 of pregnancy in mice (Carmeliet et al., 1996; Ferrara et al., 1996). In all of these embryos, marked cardiovascular defects were observed, such as delayed or abnormal development of the heart, aorta, major vessels and extraembryonic vasculature, including the yolk sac and placenta. These observations indicate a central role for VEGF not only in angiogenesis but also in organization and maintenance of the microvasculature.

Although VEGF mRNA is present in the ovine corpus luteum throughout the oestrous cycle, its abundance is two- to threefold higher early in the cycle, when luteal vascularization is occurring, compared with mid- or late cycle (Redmer and Reynolds, 1996; Doraiswamy, 1998). Although only about $30 \%$ of the endothelial mitogenic activity produced by the early ovine corpus luteum was neutralized with an anti-VEGF antibody, $65 \%$ of the endothelial migration-stimulating activity was neutralized (Doraiswamy, 1998). On the basis of these observations, we have suggested that VEGF plays a major role in luteal vascular development (Redmer and Reynolds, 1996; Reynolds and Redmer, 1998).

Consistent with the mRNA and immunoneutralization studies, localization of VEGF protein appeared to be greatest during early luteal development and least late in the oestrous cycle, during luteal regression (Doraiswamy, 1998). In addition, VEGF was expressed by connective tissue cells in the luteal capsule and connective tissue tracts, in cells within the luteal parenchymal lobules, and in luteal arterioles. The VEGF-expressing cells within the parenchymal lobules were associated with the luteal capillaries and, based on their anatomical location, appeared to be capillary pericytes. Recently, we confirmed that these cells are capillary pericytes by co-localization of VEGF and smooth muscle $\alpha$ actin, which is a specific marker of cells of the smooth muscle lineage, including pericytes (Hirschi and D'Amore, 1996; Doraiswamy, 1998). Thus, VEGF protein is localized to thecal-derived connective tissue tracts, arteriolar smooth muscle, and capillary pericytes of the developing corpus luteum. In agreement with these observations, we have shown that VEGF is expressed exclusively in the theca and not the granulosa of preovulatory bovine and ovine follicles. In addition, the thecal-derived VEGF-expressing cells invade the granulosa within hours after ovulation, before invasion of the granulosa by the thecal-derived endothelial cells (Doraiswamy, 1998).

These observations are consistent with several seemingly disparate observations made previously. First, the thecal-derived cells are responsible for vascularization of the developing corpus luteum (Zheng et al,, 1993; Reynolds et al,, 1994). Second, the thecal cells are mesodermal in origin, and the pattern of vascularization as well as VEGF expression of the developing corpus luteum closely resembles that of embryonic organs and placenta, which are vascularized by mesodermally-derived cells (Reynolds et al, 1994; Hirschi and D'Amore, 1996; Redmer and Reynolds, 1996; Doraiswamy, 1998). Third, within the last decade it has been proposed that capillary pericytes are the primary vascular cells that initiate the process of angiogenesis and subsequently interact closely with the endothelial cells to establish the mature vascular bed (Folkman and D'Amore, 1996; Hirschi and D'Amore, 1996).

These observations, taken together with studies showing that VEGF is critical for normal vascular development, led us to propose a novel model for vascularization of the corpus luteum (Fig. 4; Doraiswamy, 1998; Reynolds and Redmer, 1998). In this model, the pericytes of the thecal capillaries produce VEGF (Fig. 4a). Just before ovulation, the theca prepares to invade the membrana 


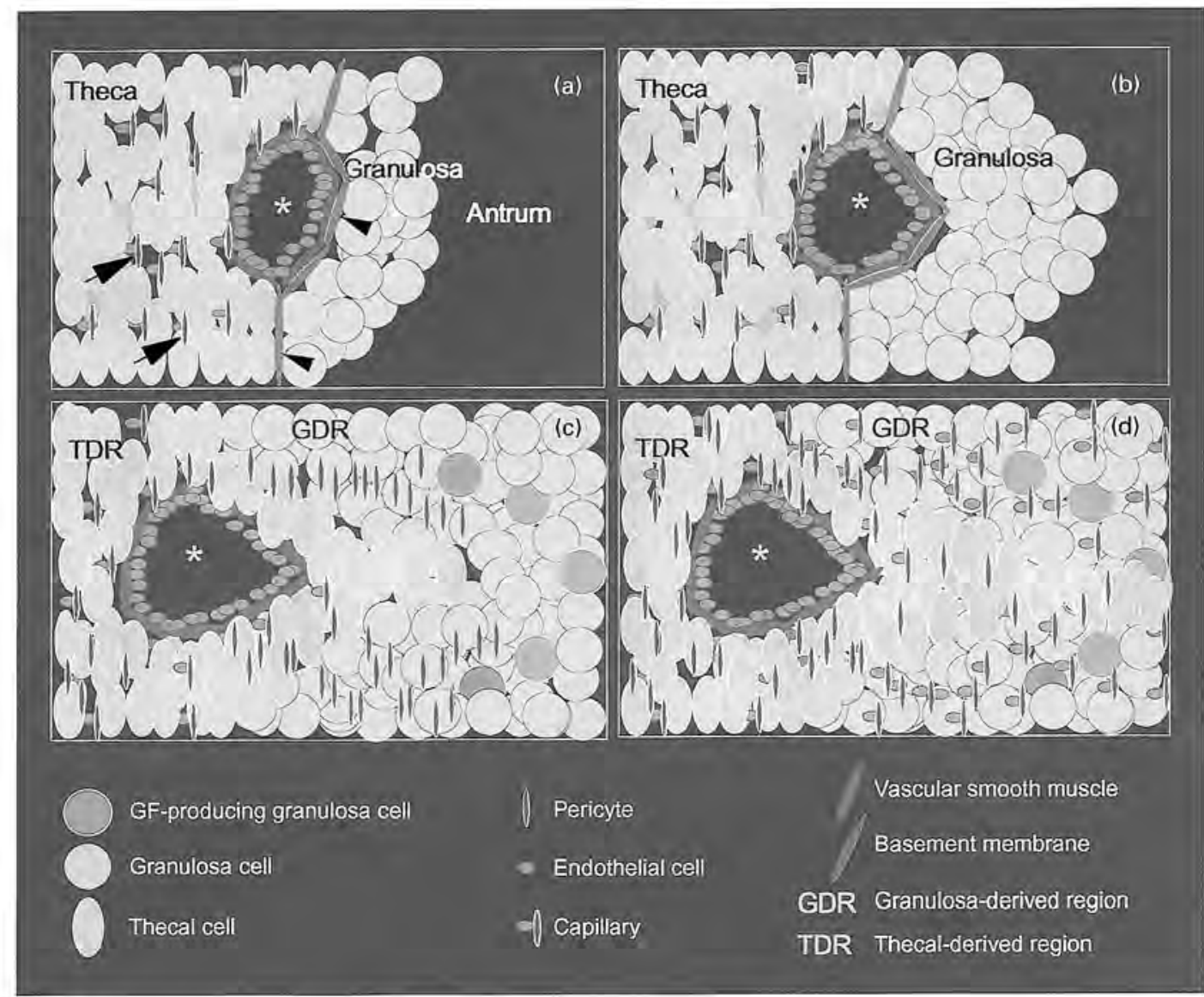

Fig. 4. Model for neovascularization of the corpus luteum. In the large preovulatory follicle (a), note the extensive network of thecal capillaries (arrows), composed of endothelial cells and pericytes, and also the larger thecal microvessels $\left({ }^{*}\right)$ separated from the avascular membrana granulosa by a basement membrane (arrowheads). A few hours before ovulation (b), the granulosal layer expands, and the larger thecal microvessels increase in size and invaginate the basement membrane. At or shortly after ovulation (c), thecal-derived pericytes migrate into the granulosal-derived region under the influence of growth factor (GF), perhaps fibroblast growth factor 2 (FGF-2) or platelet-derived growth factor (PDGF), produced by the granulosal cells. As the corpus luteum develops $(\mathrm{d})$, pericytes within the granulosal-derived region produce vascular endothelial growth factor (VEGF), which stimulates migration of thecal-derived endothelial cells; subsequently, the pericytes and endothelial cells form the mature capillary bed of the luteal parenchymal lobule. Figure modified from Doraiswamy (1998).

granulosa, which is undergoing expansion (Fig. 4b). After ovulation and breakdown of the basement membrane, the thecal-derived pericytes are the initial vascular cells that invade the granulosalderived region (Fig. 4c). Furthermore, we propose that proliferation and migration of thecal pericytes is stimulated by growth factors (GF) produced by the granulosa (Fig. 4c and d), most likely FGF-2 or platelet-derived growth factor (PDGF), both of which have been shown to stimulate pericyte migration or proliferation and may be present in the granulosa (Neufeld et al., 1987; VanWezel et al., 1995; Folkman and D'Amore, 1996). The pericytes then produce VEGF, which stimulates migration of the thecal-derived endothelial cells into the granulosal-derived region (Fig. 4d). Subsequently, the pericytes and endothelial cells form the mature capillary bed of the luteal parenchymal lobule (Fig. 4d). 


\section{Gap Junctions in Luteal Growth and Development}

\section{General aspects}

Another important means of coordinating function among the various populations of luteal cells is by contact-dependent mechanisms, which involve direct coupling of the cells via gap junctions (Grazul-Bilska et al, 1997, 1998a). Coordination of cellular functions is critical since, for example, growth of the vascular beds must be coordinated closely with tissue growth to ensure normal function of the mature corpus luteum (Klagsbrun and D'Amore, 1991; Reynolds et al., 1992).

The gap junction, nexus, or junctio communicans, is an intercellular junction that allows communication and electrical coupling between adjacent cells, and which can be open or closed (that is, a gated channel; Grazul-Bilska et al., 1997, 1998a). Gap junctions are composed of protein subunits termed connexins and are ubiquitous in multicellular organisms (Grazul-Bilska et al., 1997, 1998a). In fact, gap junctions are present in almost all mammalian tissues and have been found in ovarian follicles and corpora lutea of numerous species (Grazul-Bilska et al., 1997, 1998a).

\section{Gap junctions in luteal function}

The presence of functional gap junctions as well as gap junctional connexins in bovine and ovine luteal tissues and cultured luteal cells has recently been shown (Grazul-Bilska et al., 1997, 1998a). In addition, the concentrations and function of luteal gap junctions vary with the stage of luteal development. For example, luteal expression of connexin 43 is greater during the early and midluteal phases compared with the late luteal phase (Grazul-Bilska et al., 1997, 1998a; Khan-Dawood et $a l ., 1996)$, Luteal gap junction expression and function are regulated by luteotrophic and luteolytic hormones and second messengers (Grazul-Bilska et al., 1997, 1998a). Moreover, the rate of gapjunctional intercellular communication varies with luteal cell type; it is greatest between small luteal cells, least between large luteal cells, and intermediate between large and small luteal cells (GrazulBilska et al., 1997, 1998a).

On the basis of these observations and the known roles of gap junctions in other tissues, we proposed that gap junctions play a critical role in luteal development and function (Grazul-Bilska et al., 1997, 1998a). In support of this proposal, we have now shown that transfection of bovine luteal cells with an antisense oligonucleotide corresponding to the sequence of bovine connexin 43 not only reduced the rate of gap junctional communication but also reduced $\mathrm{LH}$-induced progesterone secretion, while not affecting basal progesterone secretion (Grazul-Bilska et al., 1998b).

By using dual immunostaining techniques, we have localized connexin 43 to the cellular borders between luteal steroidogenic and endothelial cells (Grazul-Bilska et al., 1997). Thus, gap junctions may be important in coordinating growth and function among the various types of luteal cell, including parenchymal cells, endothelial cells and pericytes (Grazul-Bilska et al., 1997, 1998a). This type of coordination may be especially important in light of our observations cited above concerning the potential importance of pericytes in luteal growth and vascularization.

\section{Conclusion}

In the last decade, we have learned much about cellular growth and cellular interactions in the corpus luteum. For example, we have determined the patterns of cell proliferation and identified the major angiogenic factors that regulate luteal vascular development. In addition, we have shown that gap junctional intercellular communication probably plays an important role in coordinating cellular functions during luteal growth and development.

However, there are many questions remaining concerning the mechanisms regulating luteal growth and development. For example, what are the roles of angiogenic factors in differentiated luteal function or luteal regression? Do additional factors play a role in maturation of the luteal microvasculature, as proposed for other systems (Folkman and D'Amore, 1996)? What are the other 
factors involved in intercellular communication among the various types of luteal cell, and do gap junctions play a role in this? What roles do gap junctions play during luteal regression: for example, do they transduce the luteolytic signal from the large luteal cells, which contain the majority of PGF receptors, to the small luteal cells? Thus, even fhough we have made substantial progress in our understanding of cellular interactions during luteal growth and development, much remains to be learned.

Work from our laboratories has been supported by grants from the US Department of Agriculture (National Research Initiafive), National Institutes of Health, and National Science Foundation. The authors would like to thank colleagues (Anna Grazul-Bilska, Derek Killilea, and Robert Moor), technicians (James Kirsch and Kim Kraft), and former students (Vinayak Doraiswamy, Paul Fricke, Albina Jablonka-Shariff, Mary Lynn Johnson, William Ricke, and Jing Zheng) without whom it would not have been possible to accomplish this work.

\section{References}

Baserga R (1985) The Biology of Cell Reproduction Harvard University Press, Cambridge, MA

Carmeliet P, Ferreira V, Breier G, Pollefeyt S, Kieckens L et al. (1996) Abnormal blood vessel development and lethality in embryos lacking a single VEGF allele Nature 380 435-439

Conley AJ, Kaminski MA, Dubowsky SA, Jablonka-Shariff A, Redmer DA and Reynolds LP (1995) Immunohistochemical localization of $3 \beta$-hydroxysteroid dehydrogenase and P450 17a-hydroxylase during follicular and luteal development in pigs, sheep and cows Biology of Reproduction 52 1081-1094

Doraiswamy V (1998) Angiogenesis in the ovine ovary: expression of vascular endothelial growth factor (VEGF) and fibroblast growth factor (FGF) PhD Dissertation North Dakota State University, Fargo

Farin CE, Moeller CL, Sawyer HR, Gamboni F and Niswender GD (1986) Morphometric analysis of cell types in the ovine corpus luteum throughout the estrous cycle Biology of Reproduction 35 1299-1308

Ferrara N and Davis-Smyth T (1997) The biology of vascular endothelial growth factor Endocrine Reviews 18 4-25

Ferrara N, Moore KC, Chen H, Dowd M, Lu L, O'Shea KS, Braxton LP, Hillian KJ and Moore MW (1996) Heterozygous embryonic lethality induced by targeted inactivation of the VEGF gene Nature $380439-442$

Folkman, J and D'Amore PD (1996) Minireview. Blood vessel formation: What is its molecular basis? Cell 87 $1153-1155$

Fong GH, Rossant J, Gertsenstein M and Breitman ML (1995) Role of the flt-1 receptor tyrosine kinase in regulating the assembly of vascular endothelium Nature 376 66-70

Gore-Langton RE and Armstrong DT (1988) Follicular steroidogenesis and its control. In The Physiology of Reproduction pp 331-385 Ed. E Knobil and J Neill, Raven Press, New York

Gospodarowicz D, Moran J, Braun DL and Birdwell CR (1976) Clonal growth of bovine vascular endothelial cells: fibroblast growth factor as a survival agent Procedings of the National Acidemy of Scicnces USA 73 4120-4124

Gospodarowicz D, Massoglia S, Cheng J and Fujii DK (1986) Effect of fibroblast growth factor and lipoproteins on the proliferation of endothelial cell derived from bovine adrenal cortex, brain cortex and corpus luteum capillaries Journal of Cell Physiology 127 121-136

Grazul-Bilska AT, Redmer DA, Killilea SD, Kraft KC and Reynolds
LP (1992) Production of mitogenic factor(s) by ovine corpora lutea throughout the estrous cycle Endocrinology $1303625-3632$

Grazul-Bilska AT, Redmer DA, Jablonka-Shariff A, Biondini ME and Reynolds LP (1995) Proliferation and progesterone production of ovine luteal cells from several stages of the estrous cycle: effects of fibroblast growth factors and luteinizing hormone Canadian Journal of Physiolozy and Pharmacology 73 491-500

Grazul-Bilska AT, Reynolds LP and Redmer DA (1997) Minireview: gap junctions in the ovaries Biology of Reproduction 57 947-957

Grazul-Bilska AT, Reynolds LP and Redmer DA (1998a) Cellular interactions in the corpus luteum Seminars in Reproductive Endocrinology 15 383-393

Grazul-Bilska AT, Reynolds LP and Redmer DA (1998b) Transfection of bovine luteal cells with gap junctional connexin $43(\mathrm{C} \times 43)$ antisense oligonucleotide affects progesterone secretion Biology of Reproduction 58 (Supplement 1) 78

Hirschi KK and D'Amore PA (1996) Pericytes in the microvasculature Cardiovascular Research 32 687-698

Hudlicka O (1984) Development of microcirculation: capillary growth and adaptation. In Handbook of Physiology, Section 2: The Cardiovascular System, Vol IV Microcirculation, Part 1 pp 165-216 Ed. EM Renkin and CC Michel. American Physiological Society, Waverly Press, Baltimore

Jablonka-Shariff A, Grazul-Bilska AT, Redmer DA and Reynolds LP (1993) Growth and cellular proliferation of ovine corpora lutea throughout the estrous cycle Endocrinology $1331871-1879$

Jablonka-Shariff A, Grazul-Bilska AT, Redmer DA and Reynolds LP (1997) Cellular proliferation and fibroblast growth factors in the corpus luteum during early pregnancy in ewes Growth Factors 14 15-23

Khan-Dawood FS, Yang J and Dawood Y (1996) Expression of gap junction protein connexin-43 in the human and baboon (Papio anubis) corpus luteum Joumal of Clinical Endocrinology and Metabolism 81 835-842

Kim KJ, Li B, Winer J, Armanini M, Gillett N, Phillips HS and Ferrarra N (1993) Inhibition of vascular endothelial growth factor-induced angiogenesis suppresses tumour growth in tivo. Nature $362841-844$

Klagsbrun MA and D'Amore PA (1991) Regulators of angiogenesis Annual Review of Physiology 53 217-239

Neufeld G, Ferrara N, Schweigerer L, Mitchell R and 
Gospodarowicz D (1987) Bovine granulosa cells produce basic fibroblast growth factor Endocrinology 121 597-603

Niswender GD and Nett TM (1988) The corpus luteum and its control. In The Physiology of Reproduction pp 489-525 Ed. E Knobil and I Neill. Raven Press, New York

Niswender GD, Schwall RH, Fitz TA, Farin CE and Sawyer HR (1985) Regulation of luteal function in domestic ruminants: new concepts Recent Progress in Hormone Research 41 101-150

Nowak RM (1991) Walker's Mantmals of the World. The Johns Hopkins University Press, Baltimore and London

Redmer DA and Reynolds LP (1996) Angiogenesis in the ovary Reviews of Reproduction 1 182-192

Redmer DA, Kirsch JD and Grazul AT (1987) In titro production of angiotropic factor by bovine corpus luteum: partial characterization of activities that are chemotatic and mitogenic for endothelial cells. In Regulation of Otarian and Tesiticular Function, Advances in Experimental Medicine and Biology Vol. 219 pp 683-688 Ed. VB Mahesh ef al. Plenum Press, New York

Redmer DA, Grazul AT, Kirsch JD and Reynolds LP (1988) Angiogenic activity of bovine corpora lutea at several stages of luteal development Joumal of Reproduction and Fertility 82 627-634

Reynolds LP (1986) Utero-ovarian interactions during early pregnancy: role of conceptus-induced vasodilation Joumal of Animal Science 62 (Supplement 2) 47-61

Reynolds LP and Redmer DA (1998.) Expression of the angiogenic factors, basic fibroblast growth factor (bFGF) and vascular endothelial growth factor (VEGF), in the ovary Journal of Animal Science 76 1671-1681

Reynolds LP, Killilea SD and Redmer DA (1992) Angiogenesis in the female reproductive system FASEB Journal 6 886-892

Reynolds LP, Killilea SD, Grazul-Bilska AT and Redmer DA (1994) Mitogenic factors of corpora lutea Progress in Growth Factor Research $5159-175$

Ricke WA (1995) Cellular growth of porcine corpora lutea throughout the estrous cycle MS Thesis North Dakota State University, Fargo
Schams D, Amselgruber W, Einspanier R, Sinowatz F and Gospodarowicz D (1994) Localization and tissue concentration of basic fibroblast growth factor in the bovine corpus luteum Endocrine 2 907-912

Shalaby F, Rossant I, Yamaguchi TP, Gertsenstein M and Schuh AC (1995) Failure of blood-island formation and vasculogenesis in flk-1-deficient mice Nature 376 62-66

Stirling D, Waterman MR and Simpson ER (1991) Expression of mRNA encoding basic fibroblast growth factor, bFGF, in bovine corpora lutea and cultured luteal cells Journal of Reproduction and Fertility 91 1-8

Swann RT and Bruce NW (1987) Oxygen consumption, carbon dioxide production and progestagen secretion in the intact ovary of the day-16 pregnant rat Joumal of Reproduction and Fertility 80 599-605

Tilly JL, Billig H, Kowalski KI and Hsueh AJW (1992) Epiderma] growth factor and basic fibroblast growth factor suppress the spontaneous onset of apoptosis in cultured rat ovarian granulosa cells and follicles by a tyrosine kinasedependent mechanism Molecular Endocrinology 6 1942-1950

Van Wezel IL, Umapathysivam K, Tilley WD and Rodgers RJ (1995) Immunohistochemical localization of basic fibroblast growth factor in bovine ovarian follicles Molecular and Cellular Endocrinology 115 133-140

Yasuda T, Grinspan I, Stern J, Franceschini B, Bannerman P and Pleasure D (1995) Apoptosis occurs in the oligodendroglial lineage, and is prevented by basic fibroblast growth factor Journal of Neuroscience Research 40 306-317

Zheng J, Redmer DA and Reynolds LP (1993) Vascular development and heparin-binding growth factors in the bovine corpus luteum at several stages of the estrous cycle Biology of Reproduction 49 1177-1189

Zheng J, Fricke PM, Reynolds LP and Redmer DA (1994) Evaluation of growth, cell proliferation, and cell death in bovine corpora lutea throughout the estrous cycle Biology of Reproduction 51 623-632 